\title{
THE IMPACT OF CONGESTION ON THE COSTS OF PUBLIC TRANSPORT IN STAROGARD GDAŃSKI
}

\begin{abstract}
Congestion in the urban transport network is common not only in large agglomerations, but also in medium-sized cities in all countries that are characterized by a high level of socio-economic development. Traffic congestion has negative impact on economic, social, and environment development. The costs of congestion are borne by all users of the transport system, both drivers, passengers, entities providing transport services, as well as enterprises using freight transport services.

The purpose of the article is to discuss the results of the study on the impact of congestion on the costs of public transport in a medium-sized city. The research method consisted in the analysis of vehicle road cards, fuel consumption statements for buses belonging to the Municipal Transport Company in Starogard Gdański and the examination of real bus travel times and the scale of delays caused by congestion on individual lines.

The analysis of the data shows that the company bears much higher costs of fuel consumption, and passengers are exposed to bus arrivals and departures inconsistently with the timetable, prompting them to opt out of public transport services. This results in lower revenues from ticket sales and deterioration of the company's financial result.
\end{abstract}

Keywords: congestion, public transport, transport costs

JEL: R40, R41, R48, R49 


\section{Introduction}

Traffic congestion has become a serious problem in many cities around the world. It is a quite common and a major problem for human mobility and it still increasing in size, scope and complexity. Significant disproportions between the transport needs and the possibilities of their meeting at the desired level of quality can be seen also in Polish cities. Traffic congestion occurs not only in large metropolises and big cities, but also in medium-sized cities like Starogard Gdański.

In cities, we are dealing with a large concentration of transport needs in time and space that occur with a specific periodicity. With heavy traffic, a dense road network is conducive to congestion at crossroads, and from there, on a chain reaction basis, it moves to sections of streets between crossroads and then to neighbouring crossroads.

Traffic congestion has negative impact on economic, social, and environment development. From the economic point of view, congestion generates an increase in the costs of transport. The costs of congestion include costs of delays, growing operating costs of vehicles (mainly fuel), emissions of pollutants, as well as costs of stress resulting from disturbances in the vehicle traffic.

The purpose of the article is to discuss the results of the study on the impact of congestion on the costs of public transport in a medium-sized city. The article adopts the hypothesis that transport congestion has a significant impact on the costs and efficiency of public transport. The research was carried out at the Municipal Transport Company in Starogard Gdański. The research method consisted of analyzing vehicle road cards, bus fuel consumption statements and examining the actual bus travel times and the scale of delays caused by congestion on individual lines.

The first part of the article reviews the literature on the issue of congestion and its effects on road users. Then, the results of the study on the impact of congestion on the extension of bus travel time and on the increase in fuel costs were presented, and the level of $\mathrm{CO}_{2}$ emissions was estimated. An analysis was also made of the changes in the number of passengers carried and the mileage of vehicles in order to show adverse changes in the area of interest of residents in using public transport.

\section{Congestion and its effects - a review of the literature}

In general terms, the term "congestion" can be referred to a situation in which a good is used or consumed jointly by a larger number of buyers and the good cannot be provided as separate units. The condition of congestion is that the presence of a greater number of users or consumers of a given good will cause negative effects, consisting mainly in hindering the remaining access to these resources. The situation described above is commonly encountered in transport, where congestion occurs on a very large scale, causing a lot of nuisance and generating high costs. Congestion arises when traffic is delayed due to the presence of other vehicles (Link et al., 1999). 
Transport congestion is defined as the mutual obstruction of traffic by vehicles due to the existing connection between the speed of moving vehicles and the volume of flows in conditions of depleted infrastructure capacity. In other words, congestion is associated with such a level of vehicle traffic that exceeds the capacity of a given road, which results in a decrease in the speed of moving vehicles or a complete impediment to free movement (Weisbord et al., 2003; Goodwin, 2004). Congestion is the result of an unbalanced demand for mobility and supply of the transport system. The level of demand results from the concentration of travel in time and space. On the other hand, supply is the result of historical infrastructure, the size of investment, traffic management and other operational practices (Falcocchio and Levinson, 2015).

Problems with defining congestion arise from the fact that although it is a physical phenomenon regarding the way vehicles impede each other's movement in conditions where the demand for limited road space reaches the maximum infrastructure capacity, its determination is associated with the subjective expectations of users in relation to the performance of the road system. In addition, some use the concept of congestion quite narrowly in relation to the conditions when there is a classic traffic jam of streets or crossroads, while others use it more broadly to describe even small speed losses due to traffic volume (OECD/ECMT, 2007).

The phenomenon of congestion is the object of research because of causing negative effects on the functioning of the economy and society. The first publications on congestion appeared in the US as early as the 1960s, because it was there that congestion became the most burdensome. W.S.Vickrey's work, who laid the foundation for the theory of congestion, is considered one of the most important publications (Vickrey, 1969). Early research on congestion focused rather on technical and organizational problems, building on the achievements of technical sciences, e.g. traffic engineering. It was only later that economic research projects began to be implemented, in which, among others attempts were made to determine the economic effects of congestion, including estimating its costs.

Congestion results in a reduction in travel speed and increase in travel time, which brings costs for the economy and has a negative impact on urban areas and their residents. Time losses due to congestion cause direct economic losses for road users, but congestion also generates a number of indirect effects, including negative effects on the environment, quality of life, safety, increases stress of drivers and passengers, and also affects non-motorized road users, such as people using sidewalks or owners of properties along the road. Congestion is the cause of more frequent collisions and accidents due to the reduction in distance between vehicles (Koźlak and Wach, 2018)

The scope of direct effects of congestion is summarized in Table 1, which also contains the results of a qualitative assessment of these effects. The head of the table lists the manifestations of the negative impact of congestion, while the side lists the entities that are traffic participants who experience these negative effects. The color indicates the intensity of the impact on a five-point scale. 
Table 1. The range of congestion impacts

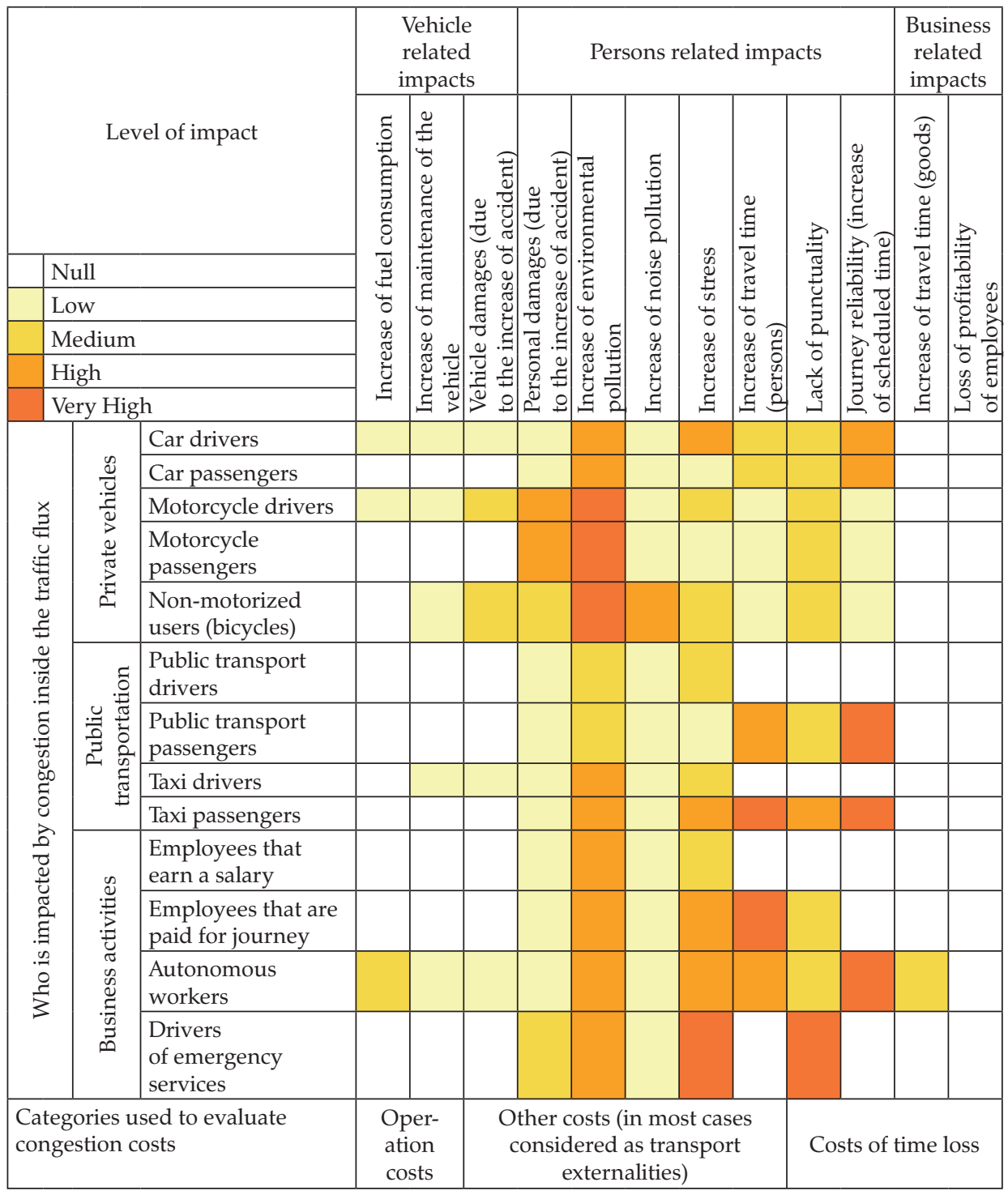

Source: (OECD/ECMT, 2007)

The effects of transport congestion can be divided into three broad categories (ECMT, 1999):

- economic effects,

- environmental effects.

- social effects. 
The costs of congestion are borne by all users of the transport system, both drivers, passengers and enterprises using freight services. The key category of congestion costs is the cost of time loss due to the extended travel time. As the travel time increases, the duration of transport peaks increases. Costs of loss of time in passenger transport occur mainly in the following types of users:

- drivers and passengers of passenger cars,

- public transport passengers and taxis,

- employees paid for the journey regardless of its duration,

- self-employed people.

In addition, losses resulting from the extension of transport time are borne both by companies that use cargo transport services and those that provide these services (transport companies, logistics operators, courier companies, etc.).

Extending the driving time is also associated with the fact that the means of transport work longer, which results in increased operating costs. During the occurrence of large congestion, when traffic takes place at low speeds, cars work in low gears and with often repeated sequence of starting, acceleration, braking and stopping, which results in increased consumption of fuel, tires, braking system components, clutch and other components (Igliński, 2009). The dependence of fuel consumption on the average speed is shown in Figure 1.



Figure 1. Average fuel consumption depending on the speed of the car Source: (OECD/ECMT, 2007)

The environmental effects of congestion are the result of the emission of harmful substances into the atmosphere, such as nitrogen oxides, carbon oxides, sulfur dioxide, solid particles and other compounds that adversely affect human health. Moving in conditions of congestion causes a significant increase in the level of emissions of harmful substances. This applies to both substances emitted from the exhaust system of the vehicle, as well as from increased use of the braking system as a result of frequent starting and stopping. These substances increase the risk of serious respiratory and cardiovascular diseases, some of which are carcinogenic. 
The group of environmental effects also includes an increased risk of accidents. Collisions between vehicles occur more often mainly because of the short distances between them while moving and the feeling of stress by drivers. Stress increases the level of aggression, adversely affects the psychophysical state, weakens concentration and contributes to the reduction of efficiency in carrying out driving activities. Although the speed of accidents is lower at a low speed (fewer injured and killed), they are more common than in conditions of free movement.

In addition to economic and environmental effects, attention should be paid to the social effects of lower speeds of movement in congestion conditions. Households usually operate on a fixed daily schedule. Various optional activities are undertaken in the free time that is at the disposal of individuals. An increase in the level of congestion, which extends the time spent on moving, may shorten the time of other activities in which household members could get involved (OECD/ECMT, 2007).

Congestion limits transport accessibility (measured by the number of people you can reach in a given time), and this may result in reduced social contact with family or friends. This may be the case if due to congestion the travel time tolerated by individuals will be regularly exceeded. Also tourist activity may be restricted in some destinations, less frequently visited due to congestion in the road network. Time losses due to congestion can fundamentally affect the spatial orientation of all human activities, including changes in the place of work and residence (ECMT, 1999).

\section{The results of the study on the impact of congestion on the costs of public transport in Starogard Gdański}

Territorial development of cities is usually associated with difficulties to meet the needs of fast movement of residents, from housing estates to places such as work, school, offices, etc. Trends related to progressing urbanization and urban sprawl necessitate constant development of the public transport network, including its density and degree of branching. Along with this, the expectations of potential users in relation to the quality and quantity of public collective transport offered by the operator increase. This is all the more important because it affects the travel time city residents must spend on travelling.

Ground-based public transport, mainly in large urban agglomerations, has to deal with the challenge of increasing street congestion and its negative impact on efficiency and functional reliability. City authorities are striving to increase the share of public transport in transport, and regular public transport will be more often used not only because of the shorter average travel time, but also because of its higher reliability and efficiency. Public transport should have a comparable or even shorter travel time compared to individual transport. Unfortunately, this is not always the case, because transport is exposed to a number of factors, the occurrence of which causes a violation of the rhythm and punctuality of vehicle traffic, which users can perceive as a decrease in the quality and efficiency of transport services. 
Usually, punctuality and availability are the main factors influencing the assessment passenger transport services. In terms of reducing the punctuality of public transport, the key importance and the growing phenomenon of congestion in transport.

The impact of congestion on the costs and effectiveness of public transport was examined on the example of Starogard Gdański, which is a medium-sized town in northern Poland. The road system in the city is based on one main route running through the town center and a number of streets crossing it that connect individual city ends. This situation causes that a large stream of vehicles traveling on the road DK 22 directly affects the possibility of smooth movement within the routes in relation to the inlet. DK 22 is a transit road connecting the eastern and western border of the country.

The article adopts the hypothesis that transport congestion has a significant impact on the costs and efficiency of public transport. To verify these dependencies, a study was carried out, on the one hand, analyzing the road card of vehicles in which daily mileage is recorded, times of departure from stops, comments of drivers about delays and their cause, fuel consumption reports for buses of the Municipal Transport Company, and on the other by the authors of the actual bus travel times on individual lines served by Municipal Transport Company Starogard Gdański and the scale of delays caused by congestion.

In Starogard Gdański, as in other cities, public transport vehicles run according to a strictly defined distribution assigned to each stop. Efficiency from the passengers' point of view may mean compliance with departure times from individual stops.

The observations carried out were grouped by day of the week and time interval. Due to the day of the week, one group includes trips on business days from Monday to Friday, while the other includes trips on Saturday and Sunday. Both groups were divided into four hour intervals: 7a.m.-9a.m., 1p.m.-3p.m., 3p.m.-5p.m., 5p.m.-7p.m. In the periods 4a.m.-7a.m., 9a.m.-1p.m. and 7p.m.-11p.m. there were no delays in the communication, so they were omitted in the list. For the separated periods, deviations of travel time were calculated in relation to the time expected in the bus timetable. Table 2 illustrates the minute deviations of bus routes from the agreed timetable.

Table 2. Delays of travel time on the surveyed lines (in minutes, within one course)

MONDAY-FRIDAY

\begin{tabular}{|c|c|c|c|c|}
\hline Line number & Times.-9a.m. & 1p.m.-3p.m. & 3p.m.-5p.m. & 5p.m.-7p.m. \\
\hline 12 & 3 & 6 & 4 & 1 \\
\hline 14 & 1 & 3 & 2 & 0 \\
\hline 16 & 5 & 13 & 9 & 3 \\
\hline 17 & 8 & 17 & 20 & 7 \\
\hline 19 & 6 & 15 & 11 & 5 \\
\hline $15 / 25$ & 6 & 12 & 14 & 5 \\
\hline
\end{tabular}


SATURDAY-SUNDAY

\begin{tabular}{|c|c|c|c|c|}
\hline Line number $\quad$ Times & 7a.m.-9a.m. & 1p.m.-3p.m. & 3p.m.-5p.m. & 5p.m.-7p.m. \\
\hline 12 & 0 & 0 & 0 & 0 \\
\hline 14 & 0 & 0 & 0 & 0 \\
\hline 16 & 0 & 4 & 1 & 0 \\
\hline 17 & 0 & 3 & 2 & 0 \\
\hline 19 & 2 & 5 & 3 & 0 \\
\hline $15 / 25$ & 0 & 3 & 1 & 0 \\
\hline
\end{tabular}

Source: own study based on the results of the research.

As can be seen from the Table 2, the greatest delays occurred from Monday to Friday, on lines 16, 17, 19, 15/25, especially during the so-called morning (from about 7a.m. to 9a.m.) and afternoon communication summit (from 1p.m. to 5p.m.). Disruptions in the movement of buses could have been influenced by increased traffic and pedestrians crossing the road, which forces the vehicle to stop frequently. In the case of Saturday and Sunday delays were significantly smaller and limited only to 1 p.m.-5p.m. Particularly difficult situation occurs on line 17, which is served by one bus. It often happens that the delays reach up to 20 minutes, and this means that in order to ensure continuity of traffic, the Municipal Transport Company dispatch service must start an additional bus. This situation is associated with additional costs in the form of financing the additional fuel consumed and the costs of operating the vehicle.

While in the case of a transport company it is relatively easy to estimate the additional financial costs resulting from delays, the matter becomes more complicated when determining the costs arising from the loss of credibility and image of the transport company, and consequently the resignation of some customers from its services. Table 3 presents data on the number of passengers transported and vehicle kilometers traveled in the years 2009-2014, which confirm the decrease in travelers' interest in public transport.

Table 3. Exploitation of buses and the number of passengers transported in 2009-2014

\begin{tabular}{|c|c|c|c|c|}
\hline Year & $\begin{array}{c}\text { Operational work } \\
\text { (vehicle-kilometres) }\end{array}$ & $\begin{array}{c}\text { Reduction } \\
\text { of the number } \\
\text { of vehicle-kilometres* }\end{array}$ & $\begin{array}{c}\text { Number } \\
\text { of passengers } \\
\text { transported }\end{array}$ & $\begin{array}{c}\text { Reduction } \\
\text { in the number } \\
\text { of passengers* }\end{array}$ \\
\hline 2009 & 1649700 & - & 4605200 & - \\
\hline 2010 & 1532600 & 117100 & 4343900 & 261300 \\
\hline 2011 & 1466800 & 65800 & 4170200 & 173700 \\
\hline 2012 & 1441100 & 25500 & 3964100 & 206100 \\
\hline 2013 & 1404500 & 36800 & 3923200 & 40900 \\
\hline 2014 & 1388800 & 15700 & 3839900 & 83300 \\
\hline
\end{tabular}

* Compared to the previous year

Source: own study based on data from the Starogard Gdański Town Hall (Załącznik do Uchwały Rady Miasta Starogard Gdański Nr XVI/157/2015). 
The data in Table 3 shows that over five years the number of passengers decreased by 765,300 people $(16.6 \%)$ and the number of driven kilometers by $260,900 \mathrm{~km}$ $(15.8 \%)$. This phenomenon was caused by an increase in the number of passenger cars at the disposal of residents and a smaller interest in public transport resulting largely from a decrease in bus punctuality and a loss of trust in the reliability of services provided by the Municipal Transport Company in Starogard Gdański. In the analyzed period, the number of traveled kilometers was also decreasing, but it was not a decrease proportional to the decrease in the number of passengers transported. The reduction in the number of passengers transported results in a reduction in revenues from ticket sales, which for the company is associated with a deterioration of the financial result.

Another variable that has been analyzed is the cost of fuel consumption by city buses, which is directly affected by the phenomenon of transport congestion. Having data on average fuel consumption, an additional cost was calculated that the Municipal Transport Company had to incur in Starogard Gdański to ensure that the company functions properly if possible. On the other hand, the additional fuel consumption was calculated by how much $\mathrm{CO}_{2}$ emissions into the atmosphere increased. Although the emission of harmful substances makes up the external costs of transport and this parameter does not have a direct impact on the operating costs of the Municipal Transport Company, the authors believe that it is worth considering it in the analysis of the effects of congestion to be aware of the importance of the combustion of each additional liter of fuel for the environment.

Table 4 presents fuel consumption and $\mathrm{CO}_{2}$ emissions during bus operation. The calculations were made on the basis of a summary of fuel consumption by the Municipal Transport Company in Starogard Gdański vehicles from 7 October 2019 to 20 October 2019.

Table 4. Fuel consumption by buses and CO2 emissions (from 7 October 2019 to 20 October 2019)

\begin{tabular}{|l|c|c|c|c|c|}
\hline \multicolumn{1}{|c|}{ Days of the week } & $\begin{array}{c}\text { Average fuel } \\
\text { consumption } \\
\text { (at 100km) }\end{array}$ & $\begin{array}{c}\text { Vehicle- } \\
\text { kilometres }\end{array}$ & $\begin{array}{c}\text { Total fuel } \\
\text { consumption }\end{array}$ & Fuel cost & $\begin{array}{c}\mathrm{CO}_{2} \\
\text { emission }\end{array}$ \\
\hline Monday-Friday & 37.31 & 45,556 & $16,996.94$ & $84,134.87$ & $39,942.82$ \\
\hline Saturday-Sunday & 33.58 & 10,687 & $10,687.00$ & $52,900.65$ & $25,114.45$ \\
\hline
\end{tabular}

Source: own study based on data from the Municipal Transport Company in Starogard Gdański (2019).

Calculations for $\mathrm{CO}_{2}$ emissions were made based on the US Department of Energy data. It reports that the motor vehicle's consumption of one liter of fuel is on average $2.35 \mathrm{~kg} \mathrm{CO}_{2}$ emissions (U.S. Energy Information Administration, 2017). However, it should be remembered that $\mathrm{CO}_{2}$ emissions from car exhausts are only a part of $\mathrm{CO}_{2}$ emitted into the atmosphere, because in order to produce one liter of fuel, oil is first extracted, then transported to a refinery, where it is processed, and finally transported as fuel for petrol stations, which is also associated with 
additional $\mathrm{CO}_{2}$ emissions. So, in fact, burning 1 liter of fuel is associated with even greater $\mathrm{CO}_{2}$ emissions into the atmosphere (Gierszewski, 2019).

The difference in average fuel consumption per $100 \mathrm{~km}$ between working days and non-working days, allows to calculate how much the fuel costs incurred by the Municipal Transport Company increased in a two-week cycle and how much $\mathrm{CO}_{2}$ emissions into the atmosphere have increased as a result. The results obtained are shown in Table 5.

Table 5. Additional fuel consumption and cost, and an increase in $\mathrm{CO} 2$ emissions from traffic in congestion conditions

\begin{tabular}{|l|c|c|c|c|}
\hline \multicolumn{1}{|c|}{ Days of the week } & $\begin{array}{c}\text { Average fuel } \\
\text { consumption } \\
(1 \text { liter } / 100 \mathrm{~km})\end{array}$ & $\begin{array}{c}\text { Fuel } \\
\text { consumption } \\
\text { (liter) }\end{array}$ & Fuel cost (PLN) & $\begin{array}{c}\mathrm{CO}_{2} \text { emissions } \\
\text { (kilogram) }\end{array}$ \\
\hline $\begin{array}{l}\text { Monday-Friday } \\
\text { (current traffic) }\end{array}$ & 37.31 & $16,996.94$ & $84,134.87$ & $39,942.82$ \\
\hline $\begin{array}{l}\text { Monday-Friday } \\
\text { (traffic without } \\
\text { congestion) }\end{array}$ & 33.58 & $15,297.70$ & $75,712.38$ & $35,944.25$ \\
\hline $\begin{array}{l}\text { Increase in parameters } \\
\text { in congestion } \\
\text { conditions }\end{array}$ & 3.73 & $\mathbf{1 , 6 9 9 . 2 4}$ & $\mathbf{8 , 4 1 1 . 2 4}$ & $\mathbf{3 , 9 9 8 . 5 7}$ \\
\hline
\end{tabular}

* Vehicle-kilometers at 45,556 km, cost of a liter of diesel fuel PLN 4.95

Source: own study.

The calculations presented in Table 5 show that due to the congestion, the public transport operator incurs an additional cost due to increased fuel consumption of over PLN 8,400 in a two-week cycle. One should also remember about the increased operational consumption of rolling stock, which also results in additional costs incurred by the company (costs of repair services, costs of used parts). It is also important to increase $\mathrm{CO}_{2}$ emissions, which reduces the standard of living of the population.

\section{Conclusions}

Congestion is a significant problem for both society- reducing the mobility of the population and increasing the cost of transport, and for the economyincreasing the cost of its functioning. The scope of the effects of congestion is very wide, because they affect not only those who contribute to its formation (drivers and passengers of cars), but also public transport passengers or non-motorized street users. Moreover, indirectly, congestion has a negative impact on the town's residents (exposure to excessive concentrations of harmful substances in the air and noise) and companies (difficulties in accessing them, a decrease in income).

The article shows that urban public transport companies incur significant financial costs resulting from increased fuel and rolling stock consumption. Traffic flow on working days would contribute to a reduction in fuel consumption by 
1,689.24 liters, which would result in savings of PLN 8,411.24 in a two-week cycle and over PLN 200,000per year.

One of the key challenges facing the management board of the Municipal Transport Company in Starogard Gdański, as well as local government authorities that are the organizer of public transport, is to improve the efficiency of public transport to encourage residents to use this form of transport. One of the ways may be to plan timetables taking into account the risk of occurrence of factors disturbing the flow of the transport process.

Passengers using public transport appreciate the reliability of transport, understood as regular service without delays. Knowing the timetable, they can plan to arrive at the bus stop in such a way that the waiting time for the vehicle is reduced to the necessary minimum. These expectations can be met by the introduction of passenger information systems at stops, which display the estimated time of arrival of the bus at the stop based on the GPS vehicle tracking system. However, this is information that the passenger would receive only after reaching the stop. It can be assumed that for the passenger more important is the information that the vehicle will arrive according to the timetable, because then the waiting time is consistent with its assumed. These investments require significant financial expenditures but significantly improve the image and opinion of the company. Therefore, efforts should be made to improve the passenger information system in this respect.

Local authorities should take care of each of the elements that can negatively affect the implementation of the transport process, including ensuring the appropriate condition of infrastructure and its modernization. Investments in transport infrastructure are one of the main tools used in the framework of regional development policy. The development of the road network leads to improved accessibility, although different effects may occur in different regions. In economic terms, each of the investments carried out is to lead to a favorable effect in the form of benefits for the region's economy or the broadly understood social factor.

Saving time, fuel, reducing $\mathrm{CO}_{2}$ emissions to the atmosphere are specific economic effects that can be achieved by reducing congestion in towns. Demonstration of these real savings can be an argument for taking all possible actions to reduce the level of congestion, especially since the GDDKiA (2015) and Transprojekt Gdańsk Sp. z o.o; (2015) data shows that transit traffic in Starogard Gdański on the urban section of the DK 22 road increases on weekdays, which significantly degree may contribute to increasing road congestion.

\section{References:}

Falcocchio, J.C., Levinson, H.S. (2015), Road traffic congestion: a concise guide, Springer International Publishing AG.

GDDKiA (2015), Generalny pomiar ruchu w 2015 roku. Średni dobowy ruch roczny w punktach pomiarowych w 2015 roku na drogach krajowych, https://www.gddkia.gov.pl/userfiles/articles/g/ generalny-pomiar-ruchu-w-2015_15598//synteza/wyniki_gpr2015_dk.pdf [Accessed 10 March 2019].

Gierszewski, M. (2019), The role of city bypasses in limiting transport congestion, Transport Economics and Logistics, 81, pp. 91-105, https://doi.org/10.26881.etil.2019.81.08. 
Goodwin, P.B. (2004), The economic costs of road traffic congestion, Discussion Paper Rail Freight Group (Transport Studies Unit, University College London), http://discovery. ucl.ac.uk/1259/1/2004_25.pdf [Accessed 20 September 2019].

Igliński, H. (2009), Ograniczanie poziomu kongestii transportowej a zrównoważony rozwój miast, Uniwersytet Ekonomiczny w Poznaniu, Poznań, http://www.wbc.poznan.pl [Accessed 26 April 2019].

Koźlak, A., Wach, D. (2018), Causes of traffic congestion in urban areas. Case of Poland, SHS Web Conf. 57, 01019, pp. 1-9, https://doi.org/10.1051/shsconf/20185701019.

Link, H., Dodgson, J.S., Maibach, M., Herry, M. (1999), The costs of road infrastructure and congestion in Europe, Physica-Verlag, Heidelberg.

OECD/ECMT (2007), Managing urban traffic congestion, OECD Publishing, Paris

Transprojekt Gdańsk Sp. z o.o. (2015), Studium korytarzowe oraz studium techniczno-ekonomiczno-środowiskowe wraz z materiałami do decyzji o środowiskowych uwarunkowaniach dla budowy Obwodnicy Starogardu Gdańskiego na parametrach drogi Gp, Tom IX - część ekonomiczna.

U.S. Energy Information Administration (2017), https://www.eia.gov/tools/faqs/faq.php? $\mathrm{id}=307 \& \mathrm{t}=11$ [Accessed 10 March 2019].

Weisbord, G., Vary, D., Treyz, G. (2003), Measuring economic costs of urban traffic congestion to business, Transportation Research Record 1839, 1, pp. 98-106, https://doi. org/10.3141\%2F1839-10.

Załącznik do Uchwały Rady Miasta Starogard Gdański Nr XVI/157/2015 z dnia 25.11.2015 r. http://edziennik.gdansk.uw.gov.pl/WDU_G/2016/34/Oryginal/akt.pdf [Accessed 15 November 2019].

\section{Corresponding author}

Marek Gierszewski can be contacted at: marek_301@wp.pl

Aleksandra Koźlakcan be contacted at: aleksandra.kozlak@ug.edu.pl 